\title{
Characterization of Skin Friction Coefficient, and Relationship to Stratum Corneum Hydration in a Normal Chinese Population
}

\author{
Y.H. Zhu ${ }^{a}$ S.P. Song ${ }^{a}$ W. Luo ${ }^{b}$ P.M. Elias ${ }^{c, d}$ M.Q. Man a,c,d \\ a Dalian Skin Disease Hospital, Dalian, and ${ }^{b}$ Department of Hygiene, Binzhou Medical College, Binzhou, PR China; \\ 'Dermatology, University of California San Francisco, School of Medicine, and d Northern California Institute for \\ Research and Education, San Francisco, Calif., USA
}

\section{Key Words}

Age $\cdot$ Gender $\cdot$ Stratum corneum hydration $\cdot$ Skin friction coefficient

\begin{abstract}
Background and Objectives: Studies have demonstrated that some cutaneous biophysical properties vary with age, gender and body sites. However, the characteristics of the skin friction coefficient in different genders and age groups have not yet been well established. In the present study, we assess the skin friction coefficient in a larger Chinese population. Methods: A total of 633 subjects ( 300 males and 333 females) aged 0.15-79 years were enrolled. A Frictiometer ${ }^{\circledR}$ FR 770 and Corneometer ${ }^{\circledR}$ CM 825 (C\&K MPA 5) were used to measure the skin friction coefficient and stratum corneum hydration, respectively, on the dorsal surface of the hand, the forehead and the canthus. Results: In the females, the maximum skin friction coefficients on both the canthus and the dorsal hand skin were observed around the age of 40 years. In the males, the skin friction coefficient on the dorsal hand skin gradually increased from 0 to 40 years of age, and changed little afterward. Skin friction coefficients on some body sites were higher in females than in age-matched males in some age groups. On the canthus and the dorsal
\end{abstract}

hand skin of females, a positive correlation was found between skin friction coefficient and stratum corneum hydration ( $p<0.001$ and $p<0.0001$, respectively). In contrast, in males, the skin friction coefficient was positively correlated with stratum corneum hydration on the forehead and the dorsal hand skin ( $p<0.05$ and $p<0.0001$, respectively). Conclusion: The skin friction coefficient varies with age, gender and body site, and positively correlates with stratum corneum hydration on some body sites.

Copyright $\odot 2010$ S. Karger AG, Basel

\section{Introduction}

Previous studies have demonstrated that some skin biophysical properties vary with gender and age. For example, the skin surface $\mathrm{pH}$ is increased in aged humans and correlates positively with age [1-3]. Although aged skin shows competent basal barrier function, the barrier recovery is delayed following acute barrier disruption above the age of 50 years [4-6]. Likewise, the skin surface sebum content also declines in an age-dependent manner $[1,3]$. Moreover, stratum corneum hydration decreases in aged skin $[1,3]$. Furthermore, cutaneous resonance running time varies with age $[7,8]$. Finally, cutaneous elastic-

\section{KARGER}

๑) 2010 S. Karger AG, Basel

Fax +41613061234 E-Mail karger@karger.ch www.karger.com www.karger.com/spp
Mao-Qiang Man, MD

Dermatology Service (190)

4150 Clement Street

San Francisco, CA 94121 (USA)

Tel. +1 415750 2091, Fax +1 415750 2106, E-Mail mqman@ hotmail.com 
Table 1. Age and gender distribution of subjects

\begin{tabular}{lllllllll}
\hline & $0-10$ years & $11-20$ years & $21-30$ years & $31-40$ years & $41-50$ years & $51-60$ years & $61-70$ years & $71-80$ years \\
\hline Male $(\mathrm{n}=300)$ & 63 & 9 & 20 & 30 & 52 & 60 & 51 & 15 \\
Female $(\mathrm{n}=333)$ & 62 & 18 & 41 & 39 & 44 & 58 & 39 & 32 \\
Total $(\mathrm{n}=633)$ & 125 & 27 & 61 & 69 & 96 & 118 & 90 & 47 \\
Mean age \pm SEM & $3.50 \pm 0.25$ & $16.11 \pm 0.61$ & $25.70 \pm 0.39$ & $36.93 \pm 0.36$ & $46.16 \pm 0.29$ & $55.08 \pm 0.27$ & $65.26 \pm 0.29$ & $75.36 \pm 0.41$ \\
\hline
\end{tabular}

ity is reduced in aged people, as a result of both decreased synthesis and accelerated degradation of collagen and elastin [9-12]. Regarding the gender differences in skin biophysical properties, previous studies have shown that the skin surface $\mathrm{pH}$ in females is higher than that in males, although a lower skin surface $\mathrm{pH}$ is also observed in females [1, 13-15]. Nevertheless, these studies suggest that there are gender differences in skin surface $\mathrm{pH}$. Additionally, the sebum content is generally higher in males than in females in normal Chinese. Similarly, gender differences in stratum corneum hydration have been observed [1]. Finally, recent studies indicate that cutaneous resonance running times also vary with gender [8]. Studies suggest that differences in sex hormones account for these gender-related differences in skin biophysical properties since the reported differences usually occurred in groups aged around 30 years, and estrogen replacement was able to change skin biophysical properties in females $[1,8,16]$.

The skin friction coefficient indicates skin surface resistance against the movement of objects on it, and it comprises another parameter of the skin's biophysical properties. Previous studies have shown that the skin friction coefficient positively correlates with stratum corneum hydration [17-22], but negatively correlates with skin oiliness [23]. While age differences in skin friction coefficient have been reported [24], most studies show no age difference [21, 22, 25-28]. In addition, Cua et al. [22, 26] have reported no gender difference in skin friction coefficient. However, variation of stratum corneum hydration with gender and age has been demonstrated $[1,3]$, and stratum corneum hydration is associated with skin friction coefficient, as noted above. Therefore, we hypothesized that the skin friction coefficient could also vary with age and gender when assessed in a homogenous population.

In the present study, we evaluated the skin friction coefficient on the dorsal surface of the hand, the forehead and the canthus in a large, normal Chinese population. Variations of skin friction coefficient with age, gender and body site were assessed.

\section{Materials and Methods}

\section{Subjects}

A total of 633 volunteers, 300 males and 333 females, aged 0.15-79 years, were enrolled in this study (table 1$)$. The subjects were divided into groups by age in decade: $0-10,11-20,21-30$, $31-40,41-50,51-60,61-70$ and $71-80$ years. All subjects had no skin disorders at the study sites. No skin care products had been applied to the measured sites for at least $24 \mathrm{~h}$ prior to the measurement, and the measured sites had not been washed with soaps or surfactants for at least $2 \mathrm{~h}$ prior to measurement.

\section{Measured Sites and Methods}

A Courage-Khazaka Frictiometer ${ }^{\circledR}$ FR 770 and Corneometer ${ }^{\circledR}$ CM 825 (C\&K MPA5) were used to measure the skin friction coefficient and stratum corneum hydration, respectively, on the dorsal surface of the hand, the forehead as well as the canthus. The tip of the Frictiometer FR 770 probe is flat and made of Teflon. The tip surface area contacting skin is $2 \mathrm{~cm}^{2}$. During the measurement of the skin friction coefficient, the normal force level was $0.7 \mathrm{~N}$ and the rotation speed $255 \mathrm{rpm}$. The units for both skin friction coefficient and stratum corneum hydration are arbitrary units. All subjects remained inactive at $16-20^{\circ} \mathrm{C}$, at a relative humidity of $44-47 \%$ for $>30$ min before measurements were taken. All studies were completed between the months of January and March, 2010, correlating with winter and early spring in northern China.

\section{Statistics}

GraphPad Prism 4 software was used for all statistical analyses. Data were expressed as means \pm SEM. The unpaired twotailed Student $t$ test with Welch correction was used to determine the significance between males and females. And one-way ANOVA with Tukey correction was used to analyze significances when 3 or more groups were compared. $\mathrm{p}<0.05$ was considered as a significant difference. All human research protocols were approved by the human research subcommittee of the Dalian Skin Disease Hospital, PR China.

\section{Results}

\section{Changes in Skin Friction Coefficient over Lifetime}

We first determined whether the skin friction coefficient changes over the lifetime. In females, indeed, skin friction coefficients on both the canthus and dorsal hand 
skin gradually increased before the age of 40 years and then declined over the lifetime, while on the forehead, skin friction coefficient positively correlated with age $\left(\mathrm{R}^{2}=0.03506 ; \mathrm{p}<0.001\right)$ (fig. 1a). In contrast, skin friction coefficients on the forehead and canthus of males did not change dramatically over the lifetime (fig. 1b). However, the skin friction coefficient on the dorsal hand skin of males increased from the age of 0 to 40 years, and remained unchanged thereafter. These results demonstrate that the skin friction coefficient varies with age in both females and males, with distinctive differences among genders.

\section{Skin Friction Coefficient Varies with Body Site}

As seen in figure 1a, in females aged 11-40 years, the skin friction coefficient was higher on the dorsal hand skin than on the forehead. Likewise, the skin friction coefficient on the canthus was also significantly higher than that on the forehead in females aged 21-50 years. However, there were no body site differences in skin friction coefficient in males except those aged 51-60 years, where the skin friction coefficient on the dorsal hand skin was significantly higher than that on the canthus and the forehead ( $\mathrm{p}<0.05$ and $\mathrm{p}<0.01$, respectively) (fig. $1 \mathrm{~b}$ ). These results indicate that the skin friction coefficient varies with body site and this variation is gender dependent.

\section{Comparison of Skin Friction Coefficient between \\ Males and Females}

Since previous studies have indicated that other skin biophysical properties vary with gender [1-3], we next assessed whether there are differences in skin friction coefficient between males and females. On the forehead, there was no difference in skin friction coefficient between males and females (fig. 2a). In contrast, on the canthus, skin friction coefficients were significantly higher in females aged 31-40 and 51-60 years than in age-matched males (fig. 2b). The skin friction coefficient on the dorsal hand skin of males aged $0-10$ years was significantly higher than that in females, while the skin friction coefficient in males aged 21-30 years was lower than that in females (fig. 2c). These results indicate that the skin friction coefficient varies not only with age, but also with gender.

\section{Changes in Stratum Corneum Hydration over}

Lifetime

As seen in figure $3 \mathrm{a}$, in females, stratum corneum hydration increased gradually from the age of 0 to 40 years and then declined. This change in hydration was more

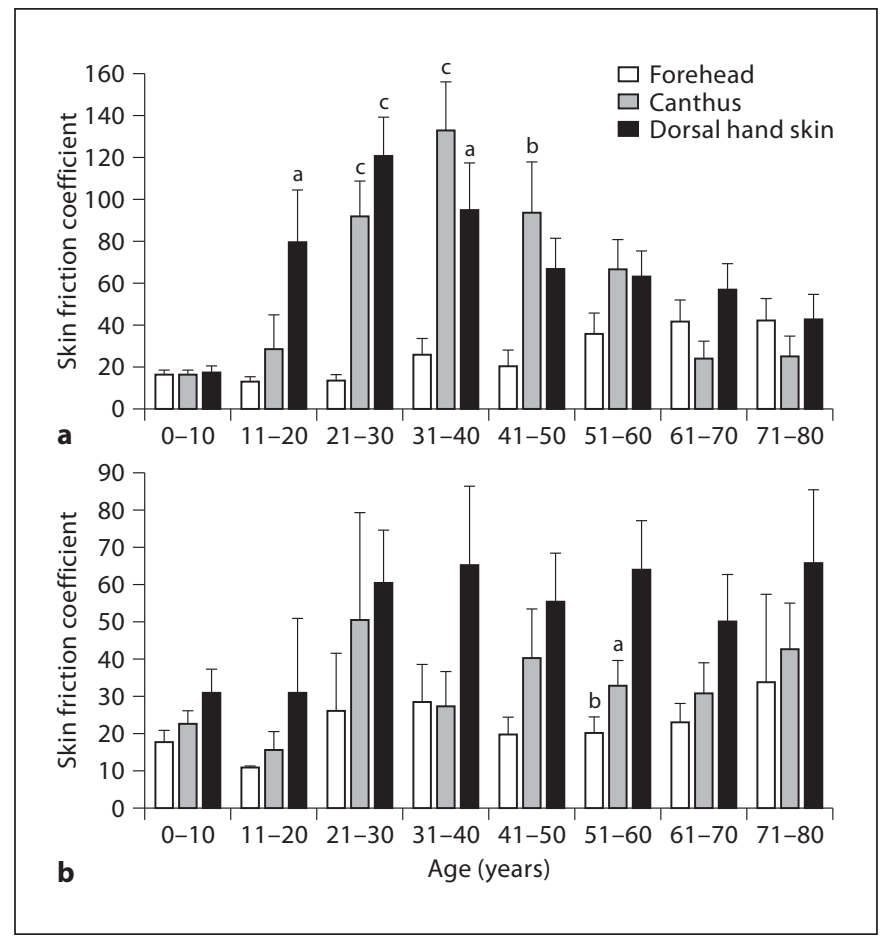

Fig. 1. Skin friction coefficient varies with body sites and age. Significant differences between body sites are shown in the figures. The number of subjects in each group is detailed in table 1 . a Body site comparison in females. ${ }^{\mathrm{a}} \mathrm{p}<0.05,{ }^{\mathrm{b}} \mathrm{p}<0.01,{ }^{\mathrm{c}} \mathrm{p}<0.001$, versus forehead. $\mathbf{b}$ Body site comparison in males. ${ }^{\mathrm{a}} \mathrm{p}<0.05,{ }^{\mathrm{b}} \mathrm{p}<0.01$, versus dorsal hand skin.

evident on the canthus $\left(\mathrm{R}^{2}=0.224\right)$ than on the forehead and dorsal hand skin. Similarly, a gradual elevation of stratum corneum hydration was observed on the canthus of males below the age of 20 years (fig. 3b). In contrast, changes in stratum corneum hydration were less impressive on the dorsal hand skin of females and males over the lifetime (fig. 3). These results demonstrate changes in stratum corneum hydration associate with age and body site in both females and males.

\section{Correlation of Skin Friction Coefficient with Stratum Corneum Hydration}

It has been shown that the skin friction coefficient is influenced by stratum corneum hydration [17-22]. We next determined the correlation of skin friction coefficient with stratum corneum hydration. In females, a significant correlation was observed between stratum corneum hydration and skin friction coefficient on the canthus and dorsal hand skin $(\mathrm{p}<0.001$ and $\mathrm{p}<0.0001$, respectively). In males, the skin friction coefficient was 


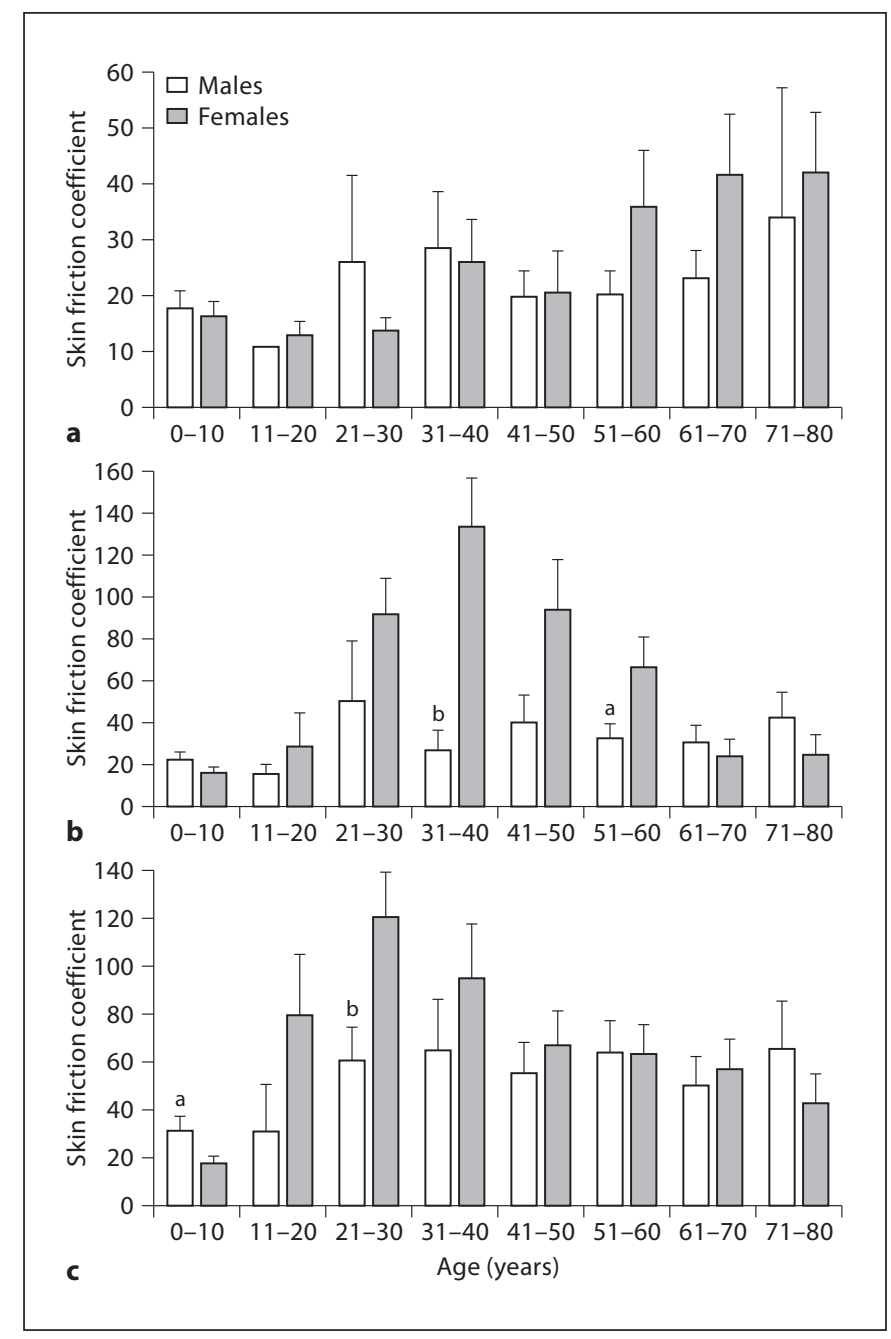

Fig. 2. Comparison of skin friction coefficient between females and males. Significant differences are shown in the figure. The number of subjects in each group is detailed in table 1. a Forehead. b Canthus. ${ }^{\mathrm{a}} \mathrm{p}<0.05 ;{ }^{\mathrm{b}} \mathrm{p}<0.0001$. c Dorsal hand skin. ${ }^{\mathrm{a}} \mathrm{p}<0.05$; ${ }^{\mathrm{b}} \mathrm{p}<0.02$.

positively correlated with stratum corneum hydration on both the forehead and dorsal hand skin $(\mathrm{p}<0.05$ and $\mathrm{p}<$ 0.0001 , respectively). These results suggest that the association of skin friction coefficient with stratum corneum hydration varies with gender and body site.

\section{Discussion}

A variety of internal and external factors influences cutaneous function, which could be reflected by the changes in skin biophysical properties. For instance, air

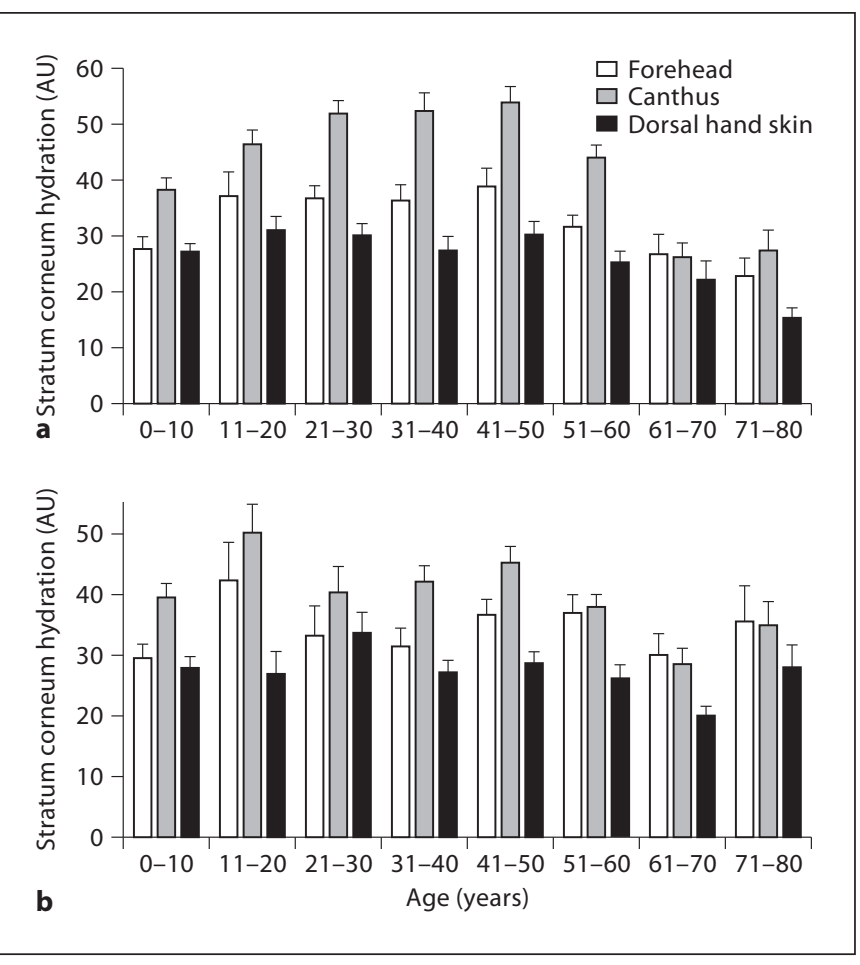

Fig. 3. Changes in stratum corneum hydration over lifetime. a Females. b Males.

pollution and smoke accelerate skin aging, as demonstrated by increased skin pigmentation and wrinkles [29]. Both chronologically aged and photoaged skin exhibit defective epidermal permeability barrier function and reduced skin elasticity [6,30-33]. And sex hormones also regulate epidermal barrier function and stratum corneum hydration $[34,35]$. The present study demonstrates that skin friction coefficient is also associated with age and gender, which is inconsistent with previous reports [21, 22, 25-28]. The resultant discrepancy could be attributed to different ethnicities studied. Prior studies have shown ethnic differences in skin biophysical properties [36-39]. The subjects in the present study are Chinese, while the majority of subjects in other studies are Caucasians. Moreover, the sample size is critical to obtain a reliable result, especially for skin biophysical properties which vary a lot among individuals. Most of the studies enrolled less than 50 subjects, which is not enough to differentiate the influences of age and gender [19, 22, 25-27]. A larger population was enrolled in the present study. Furthermore, body site is another determinant of skin biophysical properties $[1,7,22]$. In most studies, the extremities or back were measured, while in the present 
study, the canthus, which showed significant age-dependent changes in skin friction coefficient, was also measured. Thus, differences in body sites could reflect different results.

Gender differences in some skin biophysical properties have been well recognized $[1,13,40]$. However, the difference in skin friction coefficient between males and females is largely unknown. The present study shows that there are gender differences in skin friction coefficient too, which is in contrast to others' findings [22, 26, 27]. The most dramatic gender difference is found on the canthus in subjects aged $31-40$ years. The mechanism underlying this difference is not clear. This difference is most likely caused by sex hormone levels since estrogen levels are higher in females aged 31-40 years. In agreement with a previous finding [22], the present study shows a significant variation of skin friction coefficient with body site. Moreover, a positive correlation of skin friction coefficient with stratum corneum hydration is also observed in the present study, which is consistent with prior work [18, $19,21,22,41,42]$. The underlying mechanisms by which stratum corneum hydration affects the skin friction coefficient are not clear. However, previous studies suggested that hydration solubilizes proteins and, as the water dries, the adhesive properties of solubilized proteins increase skin friction [42]. Moreover, elevated stratum corneum hydration could soften the stratum corneum and increase the contact area between probe and skin, resulting in a higher skin friction coefficient [20]. Since an influence of hydration on the skin friction coefficient is only observed in some body sites, this strongly suggests that there are some other unknown factors besides hydration affecting the skin friction coefficient.

In summary, the present study shows that skin friction coefficient is associated with age, gender and body site, and positively correlates with stratum corneum hydration. This correlation is gender and body site dependent. Measurement of skin friction coefficient could be another valuable noninvasive approach to assess cutaneous function.

\section{Acknowledgments}

This study was supported in part by the National Institutes of Health grant AR 19098.

\section{Disclosure Statement}

All authors have no conflicts of interest.

\section{References}

1 Man MQ, Xin SJ, Song SP, Cho SY, Zhang XJ, Tu CX, Feingold KR, Elias PM: Variation of skin surface $\mathrm{pH}$, sebum content and stratum corneum hydration with age and gender in a large Chinese population. Skin Pharmacol Physiol 2009;22:190-199.

$\checkmark 2$ Choi EH, Man MQ, Xu P, Xin S, Liu Z, Crumrine DA, Jiang YJ, Fluhr JW, Feingold KR, Elias PM, Mauro TM: Stratum corneum acidification is impaired in moderately aged human and murine skin. J Invest Dermatol 2007;127:2847-2856.

3 Marrakchi S, Maibach HI: Biophysical parameters of skin: map of human face, regional, and age-related differences. Contact Dermatitis 2007;57:28-34.

4 Conti A, Schiavi ME, Seidenari S: Capacitance, transepidermal water loss and causal level of sebum in healthy subjects in relation to site, sex and age. Int J Cosmet Sci 1995;17: 77-85.

5 Wilhelm KP, Cua AB, Maibach HI: Skin aging: effect on transepidermal water loss, stratum corneum hydration, skin surface $\mathrm{pH}$, and casual sebum content. Arch Dermatol 1991;127:1806-1809.
6 Ghadially R, Brown BE, Sequeira-Martin SM, Feingold KR, Elias PM: The aged epidermal permeability barrier: structural, functional, and lipid biochemical abnormalities in humans and a senescent murine model. J Clin Invest 1995;95:2281-2290.

-7 Ruvolo EC Jr, Stamatas GN, Kollias N: Skin viscoelasticity displays site- and age-dependent angular anisotropy. Skin Pharmacol Physiol 2007;20:313-321.

8 Xin S, Man W, Fluhr JW, Song S, Elias PM Man MQ: Cutaneous resonance running time varies with age, body site and gender in a normal Chinese population. Skin Res Technol 2010;16:413-421.

-9 Uitto J: The role of elastin and collagen in cutaneous aging: intrinsic aging versus photoexposure. J Drugs Dermatol 2008; 7:s12 s16.

10 Leyden JJ: Clinical features of ageing skin. $\mathrm{Br}$ J Dermatol 1990;122(suppl 35):1-3.

11 Baumann L: Skin ageing and its treatment. J Pathol 2007:211:241-251.
12 Varani J, Dame MK, Rittie L, Fligiel SE, Kang S, Fisher GJ, Voorhees JJ: Decreased collagen production in chronologically aged skin: roles of age-dependent alteration in fibroblast function and defective mechanical stimulation. Am J Pathol 2006;168:18611868

13 Jacobi U, Gautier J, Sterry W, Lademann J: Gender-related differences in the physiology of the stratum corneum. Dermatology 2005; 211:312-317.

14 Ehlers C, Ivens UI, Møller ML, Senderovitz T, Serup J: Females have lower skin surface $\mathrm{pH}$ than men: a study on the surface of gender, forearm site variation, right/left difference and time of the day on the skin surface pH. Skin Res Technol 2001;7:90-94.

-15 Williams S, Davids M, Reuther T, Kraus D, Kerscher M: Gender difference of in vivo skin surface $\mathrm{pH}$ in the axilla and the effect of a standardized washing procedure with tap water. Skin Pharmacol Physiol 2005;18:247252.

16 Hall G, Phillips TJ: Estrogen and skin: the effects of estrogen, menopause, and hormone replacement therapy on the skin. J Am Acad Dermatol 2005;53:555-568. 
17 Comaish S, Bottoms E: The skin and friction: deviations from Amonton's laws, and the effects of hydration and lubrication. Br J Dermatol 1971;84:37-43.

-18 Gerhardt LC, Strässle V, Lenz A, Spencer ND, Derler S: Influence of epidermal hydration on the friction of human skin against textiles. J R Soc Interface 2008;5:1317-1328.

-19 Lodén M, Olsson H, Axéll T, Linde YW: Friction, capacitance and transepidermal water loss (TEWL) in dry atopic and normal skin. Br J Dermatol 1992;126:137-141.

20 Sivamani RK, Goodman J, Gitis NV, Maibach HI: Friction coefficient of skin in realtime. Skin Res Technol 2003;9:235-239.

-21 Egawa M, Oguri M, Hirao T, Takahashi M, Miyakawa M: The evaluation of skin friction using a frictional feel analyzer. Skin Res Technol 2002;8:41-51.

-22 Cua AB, Wilhelm KP, Maibach HI: Frictional properties of human skin: relation to age, sex and anatomical region, stratum corneum hydration and transepidermal water loss. $\mathrm{Br}$ J Dermatol 1990;123:473-479.

23 Nacht S, Close J, Yeung D, Gans EH: Skin friction coefficient: changes induced by skin hydration and emollient application and correlation with perceived skin feel. J Soc Cosmet Chem 1981;32:55-65.

24 Asserin J, Zahouani H, Humbert P, Couturaud V, Mougin D: Measurement of the friction coefficient of the human skin in vivo: quantification of the cutaneous smoothness. Colloids Surf B Biointerfaces 2000;19:1-12.

-25 Elsner P, Wilhelm D, Maibach HI: Frictional properties of human forearm and vulvar skin: influence of age and correlation with transepidermal water loss and capacitance. Dermatologica 1990;181:88-91.
26 Cua AB, Wilhelm KP, Maibach HI: Skin surface lipid and skin friction: relation to age, sex and anatomical region. Skin Pharmacol 1995;8:246-251.

27 O'Meara DM, Smith RM: Static friction properties between human palmar skin and five grabrail materials. Ergonomics 2001;44: 973-988.

28 Gerhardt LC, Lenz A, Spencer ND, Münzer T, Derler S: Skin-textile friction and skin elasticity in young and aged persons. Skin Res Technol 2009;15:288-298.

29 Morita A, Torii K, Maeda A, Yamaguchi Y: Molecular basis of tobacco smoke-induced premature skin aging. J Investig Dermatol Symp Proc 2009; 14:53-55.

>30 Fisher GJ, Wang ZQ, Datta SC, Varani J, Kang S, Voorhees JJ: Pathophysiology of premature skin aging induced by ultraviolet light. N Engl J Med 1997;337:1419-1428.

31 Vierkötter A, Schikowski T, Ranft U, Sugiri D, Matsui M, Krämer U, Krutmann J: Airborne particle exposure and extrinsic skin aging. J Invest Dermatol 2010, E-pub ahead of print.

32 Reed JT, Elias PM, Ghadially R: Integrity and permeability barrier function of photoaged human epidermis. Arch Dermatol 1997;133: 395-396.

33 Park HY, Youm JK, Kwon MJ, Park BD, Lee SH, Choi EH: K6PC-5, a novel sphingosine kinase activator, improves long-term ultraviolet light-exposed aged murine skin. Exp Dermatol 2008;17:829-836.

34 Tsutsumi M, Denda M: Paradoxical effects of $\beta$-estradiol on epidermal permeability barrier homeostasis. Br J Dermatol 2007;157: 776-779.
35 Sator PG, Sator MO, Schmidt JB, Nahavandi $\mathrm{H}$, Radakovic S, Huber JC, Hönigsmann $\mathrm{H}$ : A prospective, randomized, double-blind, placebo-controlled study on the influence of a hormone replacement therapy on skin aging in postmenopausal women. Climacteric 2007;10:320-334

-36 Diridollou S, de Rigal J, Querleux B, Leroy F, Holloway Barbosa V: Comparative study of the hydration of the stratum corneum between four ethnic groups: influence of age. Int J Dermatol 2007;46(suppl 1):11-14.

$>37$ Kompaore F, Tsuruta H: In vivo differences between Asian, black and white in the stratum corneum barrier function. Int Arch Occup Environ Health 1993;65(1 suppl):S223S225.

$>38$ Kompaore F, Marty JP, Dupont C: In vivo evaluation of the stratum corneum barrier function in blacks, Caucasians and Asians with two noninvasive methods. Skin Pharmacol 1993;6:200-207.

39 Berardesca E, Pirot F, Singh M, Maibach H: Differences in stratum corneum $\mathrm{pH}$ gradient when comparing white Caucasian and black African-American skin. Br J Dermatol 1998; 139:855-857.

40 Conti A, Schiavi ME, Seidenari S: Capacitance, transepidermal water loss and causal level of sebum in healthy subjects in relation to site, sex and age. Int J Cosmet Sci 1995;17: 77-85.

41 Naylor PFD. The skin surface and friction. Br J Dermatol 1955;67:239-248.

42 Highley DR, Coomey M, DenBeste M, Wolfram LJ: Frictional properties of skin. J Invest Dermatol 1977;69:303-305. 